16. Metrikin David C. et al. Intraocular Cilia after penetrating Eye Injury // Arch. of Ophthalmol. - 1992. - Vol.110 (7). - P.921

17. Muller, 1941. - цит. Duke-Elder, System of Ophthalmology. - 1972. - vol. XIV.

18. Olorenshaw G. M. et al. Tolerance of the Eye for implanted cilia // Br of Ophthalmology. - 1991. - V.75. - P.622-623.

19. Popov, 1941. - цит. Duke-Elder, System of Ophthalmology 1972, vol. XIV.

20. Richardson Cross and E. Trracher Collins (1893) цит по Duke Elder.

21. Rubey F. Eyelashes in the anterior chamber // Klin Monatsbl Augenheilk. - 1966. - V.149. - P.371-373.

22. Ruete цит по L. N. Savin, 1936.

23. Savin L. H. Notes on an Eyelash carried by a perforating injury into the posterior aqueous chamber and removed eleven weeks later // Br J of Ophthalmology. - 1936. P.609-612.

24. Seawright A. A. et al. Intravitreal Cilia in Phakic Penetrating Eye Injury // Aust NZJ Ophthalmol. - 1997. - May; $25(2)$. - P.133-5.
25. Stichevska O., Payne B. F., 1949 цит. Duke-Elder, System of Ophthalmology 1972, vol. XIV.

26. Talvatana Wassee and oth. Free Keratin and dermoid cyst of the Iris Arch of Ophthalmolgy 2005, v123, 3,402-403

27. Taneja Sanjeev et al. Fingernail Trauma Causing Corneal Laceration and intraocular Cilia // Arch. Ophth. 1998. - V.116. - P.530-531.

28. Wagenmann, 1921 цит. по L. N. Savin Notes on an Eyelash carried by a perforating injury into the posterior aqueous chamber and removed eleven weeks later.

29. Walker Nathan $\mathbf{J}$ and oth. Postoperative Cilium entrapment by clear corneal incision // J. Cataract and refractive Surgery. -2007 . - V.33 (2). - P.733-34

30. Wirth M. G., Helbig H. Can Eyelashes Migrate // Klin Monat Augenheilkd. - 2005. - V.222 (3). - P.238-240.

31. Yalniz-Akkaya Z $\mathbf{Z}$. Post-traumatic cilia remaining inert in the anterior chamber for 50 years: a case report // J Med Case Report. - 2011. - Oct 26; 5 (1). - P.527.

Поступила 10.05.2012

Рецензент д. М. Н. В. В. Савко

\title{
ABOUT PENETRATION OF THE EYELASHES INSIDE THE EYE
}

Krasnovid T. A., Vit V. V., Aslanova V. S., Kovalchuk A. G.

Odessa, Ukraine

There were described the four cases of penetration of the eyelashes (in one of them simultaneously 5) inside the eye observed by the authors with its penetrating injury. The peculiarities of the eye reaction to the penetration of eyelashes are noted in each of them. There was shown the diagnostic value of the ultrasonic study in detection of the eyelashes, inaccessible to visualization by biomicroscopy. Morphological studies of the removed cyst of the iris, which formed in one of the patients, give grounds to consider it due to implantation. A brief literary survey is given concerning a question of the eyelash penetration inside the eye and its possible reaction.

УДК 617.731-001.4-085-036.8

\section{ВИПАДОК УСПІШНОГО ЛІКУВАННЯ ТРАВМАТИЧНОЇ ОПТИЧНОЇ НЕЙРОПАТІЇ}

\author{
Н. М. Мойсеєнко, доцент курсу офтальмології, канд. мед. наук, І. В. Цимбалюк, лікар,
}

\section{С. В. Вершинін, лікар-інтерн, Н. Р. Сеньків, клінічний ординатор}

ДВНЗ «Івано-Франківський національний медичний університет», Івано-Франківська обласна клінічна лікарня

Вступ. Травматичні ураження зорових нервів, вперше описані Гіппократом і об'єднані в термін «травматична оптична нейропатія (ТОН)», серед пацієнтів із слабким зором зустрічаються у $43-78 \%$ [7]. Відповідно до сучасних уявлень найбільш частою причиною ТОН вважається черепно-мозкова травма. Elisevich K. V., 1994, [5] і Laura K. Windsor., 2003, [8] зазначають, що ТОН зустрічається у 0,5$3 \%$ черепно-мозкової травми, що може бути причиною посттравматичної сліпоти.

Щорічний приріст випадків дорожньотранспортних пригод, падінь з висоти, бійок із ударами лобної частини голови викликає збільшення кількості не тільки черепно-мозкових травм, а й важких поєднаних краніо-фаціальних уражень у людей молодого віку. Відомо, що за таких умов імовірність виникнення ТОН збільшується з 17 до $63 \%)[10]$.

У більшості пацієнтів легкі і початкові форми ТОН залишаються не діагностованими [6]. Діагностика ушкоджень зорового нерва часто ускладнюється через неможливість проведення всіх необхідних маніпуляцій за наявності інших небезпечних для життя травм. Як відомо, такі травми часто супроводжуються різними ступенями втрат свідомості.

(C) Н. М. Мойсеєнко, І. В. Цимбалюк, С. В. Вершинін, Н. Р. Сеньків, 2012 
Більшість ознак таких травм є суб'єктивними, а тому огляд травмованих пацієнтів у найбільш ранній період супроводжується труднощами для клініциста [11].

Andrew G. Lee, 2003, вважає, що основними ознаками ТОН є:

- пряме або непряме ушкодження голови, обличчя або орбіти;

- одностороння або двостороння втрата зору;

- транзиторна втрата гостроти зору (в діапазоні від 20/20 до відсутності світлосприйняття);

- різноманітні порушення поля зору;

- дефекти аферентної зіничної реакції (однобічні чи двобічні, асиметрія);

- нормальна офтальмоскопічна картина або, рідше, набряк зорового нерва;

- іпсілатеральна атрофія зорового нерва;

- відсутність інших причин втрати зору (травматичної катаракти, гемофтальму, відшарування сітківки [1].

Cook M. W. із співавторами виділили 4 класи важкості захворювання. Перший клас ТОН характеризується гостротою зору вище 0,1 у поєднанні 3 переломом верхівки орбіти. При другому класі гострота зору знижується від 0,1 до світловідчуття без переломів верхівки орбіти. При третьому - відсутнє світловідчуття або зміщення кісткових уламків верхівки орбіти. При четвертому - поєднання відсутнього світловідчуття та зміщення кісткових уламків верхівки орбіти [4].

Нейровізуалізація за допомогою КТ, МРТ та УЗД [12] може підтвердити діагноз. Застосування КТ в аксіальній і коронарній проекціях при ТОН дає можливість виявити крововиливи під оболонки нерва або навколо нього, біля верхівки орбіти, а також арахноїдальні кісти, переломи великого чи малого крил криловидної кістки, надкістні гематоми, геморагії в решітчаті або сфероїдальні пазухи, пневмоенцефальоз. МРТ також визначає геморагії під оболонки зорового нерва, його набряк [2].

Погляди на способи лікування ТОН різноманітні. Відповідно до ранніх уявлень, прогноз при ТОН вважався невтішним. Проте в пізніші роки більш ретельне вивчення проблеми і непоодинокі випадки успішного лікування переконали науковців у протилежному. Надалі виникла суперечність щодо доцільності лікування ТОН. Вважається, що у 20-38 \% випадків можлива нормалізація функцій зору без лікування. У той же час описані добре контрольовані випадки з хорошими результатами після проведеного лікування. Тому, на думку Cook M. W., 1996, відновлення зорових функцій відбувається з кращими перспективами на фоні лікування, ніж без нього [4].

Літературні відомості щодо ефективності медикаментозних і хірургічних способів лікування також суперечливі. Пропонується застосування монотерапії високими дозами стероїдів, або стероїдами у поєднанні з хірургічними Нижче наводимо приклад успішного поєднання пульс-терапії Сульмедролом, а також Кортексину і фосфен-стимуляції у пацієнта iз $\mathrm{TOH}$.

\section{Хворий Г. № 1936811}

Скарги: погіршення зору на ліве око.

Анамнез: отримав травму в результаті бійки, удар у ліве око 5.10.11 року. Був госпіталізований у відділення нейрохірургії, де знаходився з 5 по 17.10.11 р. Вже 7.10.11 р. було виявлено зниження зору до ОД на ліве око, у зв'язку з чим з 10.10.11 р. призначено пульс-теранію Сульмедролом, п/б Кортексин під ліве око, а 18.10.11 р. хворий переведений у відділення мікрохірургії ока.

Обстеження при надходженні в очне відділення

Гострота зору. $\mathrm{OD}=0,8 \mathrm{н} / \mathrm{k} ; \mathrm{OS}=0,3 \mathrm{н} / \mathrm{k}$

BOT $O D=19 ; O S=18$ мм рт. ст.

$\mathrm{OU}$ - спокійне, передній відрізок не змінений.

Очне дно: OD - диск зорового нерва гіперемований, стушованість носової межі, незначне виповнення фізіологічної екскавації. Вени поширені, артерії спазмовані.

OS - диск зорового нерва блідий, набряклий, межі розмиті, фізіологічна екскавація виповнена. Вени поширені, артерії спазмовані.

Клінічний діагноз: Травматична оптична нейропатія, часткова атрофія зорового нерва лівого ока. Наслідки ЗЧМТ і перелому внутрішньої стінки орбіти лівого ока.

Отримував лікування:

Місцево: OS п/б Дексаметазон, фосфен-стимуляція.

Загальне: в/в Глюзок 40 \% + Аскорбінова кислота, Пентоксифелін, Солюмедрол, в \м Емоксипін, Тіотриазолін, Кортексин,.

Обстеження при виписиі:

Гострота зору OD $=1,0 ; O S=0,8$ н/к

BOT $O D=19 ;$ OS=18 мм рт. ст.

$\mathrm{OU}$ - спокійні, передній відрізок не змінений. Очне дно: диск зорового нерва блідо-рожевий, межі чіткі, фізіологічна екскавація незначно поширена зліва, вени поширені, артерії спазмовані.

РЕЗУЛЬТАТИ І ЇХ ОБГОВОРЕННЯ. Проведене дослідження продемонструвало позитивну динаміку зорових функцій при ТОН в результаті поєднання пульс-терапії Сульмедролом, застосування Кортексину і фосфен-стимуляції. Спостерігалось підвищення гостроти/(з 0,8 до 1,0 на праве око і 3 0,3 до 0,8 на ліве око) та розширення меж поля зору (сума за 4 меридіанами становила $230^{\circ}$ для правого ока і $190^{\circ}$ для лівого ока, і в результаті лікування розширилась до 240 і $225^{\circ}$ відповідно, рис.1), що свідчить про призупинення дегенерації гангліонарних клітин сітківки [9].

При виписці показники контрастної чутливості також були кращими (рис. 2). На обох очах чутливість в діапазоні високих частот відновилась повністю, що свідчить про відновлення фукціональної здатності первинного центру зору. Проте чутливість в діапазоні низких просторових частот залишалась низькою (табл. 1).

За даними Humhrey-периметрії (рис. 3) спостерігалась позитивна динаміка відносних величин, проте збільшилась інтенсивність і площа парацентральних скотом. 


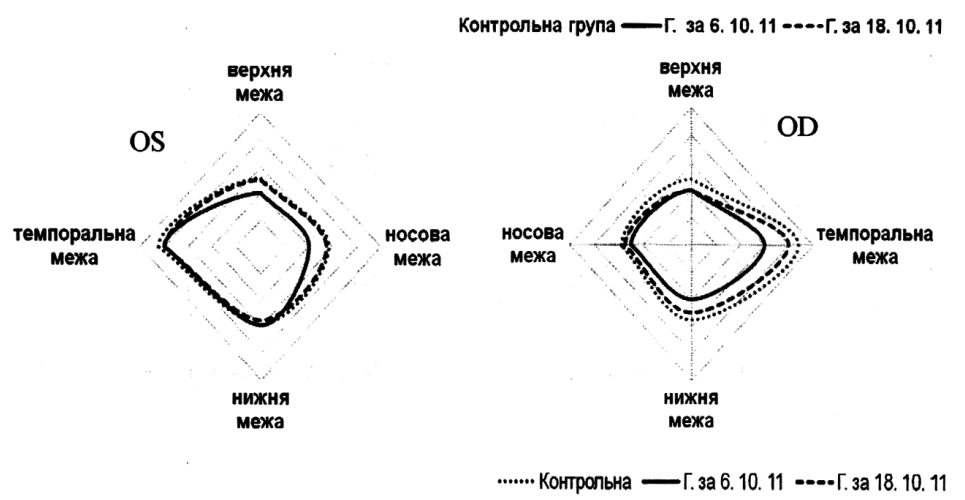

Рис. 1. Зміни периметрії

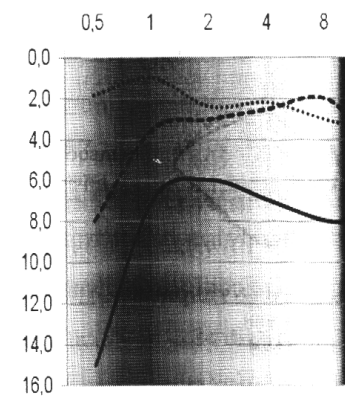

OS

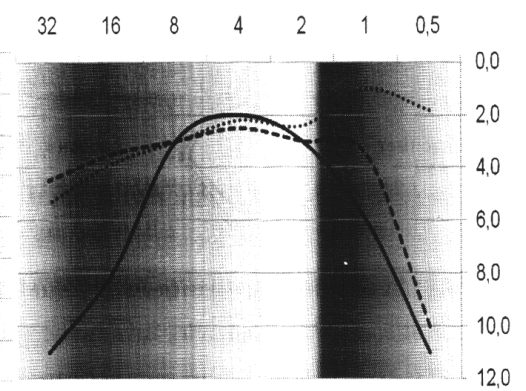

OD

Ри. 2. Контрастна чутливість до і після лікування

Таблиця

Динаміка даних Нumphrey-периметрії і фосфендіагностики хворого $\Gamma$.

\begin{tabular}{|c|c|c|c|c|}
\hline \multirow{2}{*}{ Око } & \multicolumn{2}{|c|}{$\begin{array}{c}\text { Humphrey-периметрія за } \\
\mathbf{1 4 . 1 0 . 1 1}\end{array}$} & \multicolumn{2}{c|}{$\begin{array}{c}\text { Фосфен-діагностика за } \\
\text { 19.10.11: }\end{array}$} \\
\hline & MD & PSD & ПЕЧ & ЛАБ \\
\hline OD & $-4.09 \mathrm{~dB}$ & $+5.74 \mathrm{~dB}$ & 60 & 43,1 \\
\hline OS & $-8.39 \mathrm{~dB}$ & $+6.19 \mathrm{~dB}$ & 69 & 42,1 \\
\hline & \multicolumn{2}{|c|}{ Humphreу-периметрія } & \multicolumn{2}{|c|}{$\begin{array}{c}\text { Фосфен-діагностика за } \\
27.10 .11:\end{array}$} \\
\hline OD & $-3,84 \mathrm{~dB}$ & $+3,26 \mathrm{~dB}$ & 66 & 44,5 \\
\hline OS & $-7,42 \mathrm{~dB}$ & $+4,41 \mathrm{~dB}$ & 86 & 41,2 \\
\hline
\end{tabular}

Незважаючи на значну ефективність проведеного лікування, спостереження за даним хворим викликало ряд питань, які потребують більш детального вивчення і пояснення. Незрозумілим залишається те, що показники контрастної чутливості, Humhrey-периметрії і фосфен-діагностики на правому (ніби здоровому оці, 3 початково вищою гостротою зору) погіршились після лікування, в той час як на лівому - покращились. Імовірно, дана схема сприяла призупиненню і регресу дегенеративних змін нервових волокон на лівому оці, а на правому - за відсутності відповідної терапії - прогресу. Можливо виник ефект реперфузії, що спричинило обкрадання правого ока за рахунок лівого. Все це може бути причиною зниження гостроти зору в подальшому.

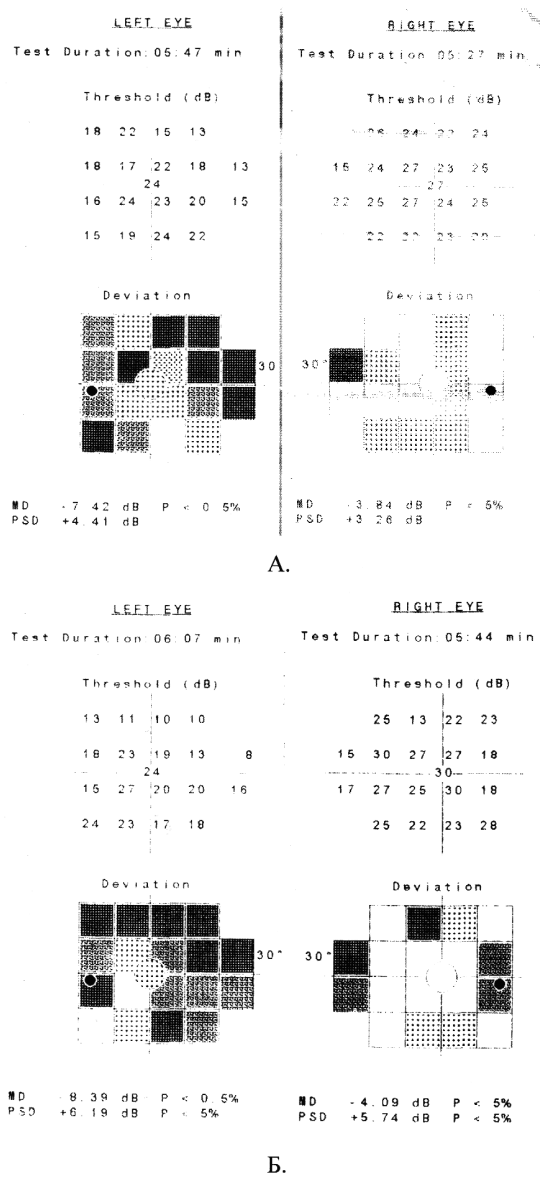

Рис. 3. Дані Нumphreу-периметрії до (А) і після (Б) лікування 
Заключения. Отже, застосування комбінації пульс-терапії Сульмедролом, Кортексину і фосфенстимуляції сприяє підвищенню ефективності лікування ТОН. Функціональні зміни з боку здорового ока, вказані вище, носять проблемний характер, що обумовлює необхідність їх більш глибокого вивчення і пояснення.

\section{ЛІТЕРАТУРА}

1. Andrew G. Lee. Clinical Pathways in Neuro-Ophthalmology An Evidence-Based Approach, Second Edition / [Andrew G. Lee, Paul W. Brazis]. - New-York-Stuttgart: Thieme, 2003. - 486 p.

2. Ayyaz Hussain Awan Traumatic Optic Neuropathy / [Ayyaz Hussain Awan] // Pak. J. Ophthalmol. - 2007. Vol. 23. - № . 2. - P. 100-102.

3. Carta A. Visual prognosis after indirect traumatic optic neuropathy / [Carta A., Ferrigno L., Salvo M., BianchiMarzoli S., Boschi A., Carta F.] // J Neurol Neurosurg Psychiatry. - 2003. - № 74. - P. 246-248.

4. Cook M. W. Traumatic optic neuropathy. A meta-analysis. / [Cook M. W., Levin L. A., Joseph M. P., Pinczower E. F.] // Arch. Otolaryngol. Head Neck Surg. - 1996. № 122. - P. 389-392.

5. Elisevich K. V. Visual abnormalities with multiple trauma / [Elisevich K. V., Ford R. M., Anderson D. P., et s.t] // Surg. Neurol. - 1994. - № 22 (6). - P. 565575.

6. Kenneth D. Steinsapir. Traumatic Optic Neuropathies / [Kenneth D. Steinsapir, Robert A. Goldberg] // Walsh \& Hoyt's Clinical Neuro-Ophthalmology, 6th Edition [Miller, Neil R., Newman, Nancy J.]. - Volume I, Section I: The Visual Sensory System. - Lippincott Williams \& Wilkins, 2005. - P. 432-446.

7. Kowal L. Ophthalmic manifestations of head injury / L. Kowal // Aust. NZ. J. Ophthalmol. - 1992. - № 2. P. $35-40$.

8. Laura K. Windsor. Hemianopsia: Loss of Half of the Visual Field After Stroke or Traumatic Brain Injury / Laura K. Windsor, Richard L. Windsor. // Vision Enhancement Journal. - 2003. - № 3. - P. 32-33.

9. Ming-Tse Kuo. Serial Follow-Up in Traumatic Optic Neuropathy Using Scanning Laser Polarimetry and Visual Field Testing / [Ming-Tse Kuo, Ing-Chou Lai, Mei-Ching Teng] // Chang. Gung. Med. J. - 2005. - Vol. 28. № 8. - P. 581-586.

10. Nau H. E, Gerhard L. Optic nerve trauma: Clinical, electrophysiological and histological remarks. / [Nau H. E, Gerhard L., Foerster M.] // Acta. Neurochir. - Wien, 1987. - 22 p.

11. Sarkies N. Traumatic optic neuropathy // Eye. - 2004. Vol. 18 - P. 1122-1125.

12. Sawhney R. Traumatic optic nerve avulsion: role of ultrasonography / [Sawhney R., Kochlar S., Gupta R., Jain R., Sood S.] // Eye. - Vol.17. - P.667-670.

Конференции, съезды

\section{BIT \\ ПРО ПРОВЕДЕННЯ НАУКОВО - ПРАКТИЧНОЇ КОНФЕРЕНЦІЇ ОФТАЛЬМОЛОГІВ ЗАКАРПАТСЬКОЇ,, ІВАНО-ФРАНКІВСЬКОЇ, ЛЬВІВСЬКОї, ТЕРНОПІЛЬСЬКОЇ, ЧЕРНІВЕЦЬКОЇ ОБЛАСТЕЙ УКРАЇНИ “АКТУАЛЬНІ ПИТАННЯ ОФТАЛЬМОЛОГІЇ»}

Н. В. Пасєчнікова, член-кореспондент НАМН України, проф., В. О. Науменко, д-р мед. наук,

О. О. Мороз, к. мед. наук,

О. Г. Стойловська, ст. Н. с.,

К. В. Мартопляс, Ст. Н. С., В. В. Мирненко, Н. С.

ДУ «Інститут очних хвороб і тканинної терапії ім. В.П. Філатова НАМН України»

ДВНЗ «Ужгородський національний університет»

26-27 квітня 2012 р. в м. Ужгород відбулася науково - практична конференція офтальмологів Закарпатської, Івано-Франківської, Львівської, Тернопільської та Чернівецької областей України «Актуальні питання офтальмології при активній участі в іiї організації і проведенні науковців ДУ «Інститут очних хвороб і тканинної терапії ім. В. П. Філатова НАМН України» та ДВНЗ «Ужгородський національний університет» при підтримці Закарпатської облдержадміністрації та обласної ради, головного управління охорони здоров'я Закарпатської облдержадміністрації.
Учасниками конференції були 345 офтальмологів, з них 73 з м. Ужгород та Закарпатської області, 73 з м. Одеса та Одеської області (56 фахівців 3 інституту ім. В.П.Філатова), 71 з м. Львів та Львівської області, 25 - м. Івано-Франківськ та ІваноФранківська область, 23 з м. Києва та Київської області, 15 з м. Тернопіль та Тернопільської області, 11 з м. Чернівці та Чернівецької області, 1 з Донецької

(C) Н. В. Пасєчнікова, В. О. Науменко, О. О. Мороз, О. Г. Стойловська, К. В. Мартопляс, В. В. Мирненко, 2012 